\title{
Patterns of body weight in the Baltic Republics
}

Joceline Pomerleau', Iveta Pudule ${ }^{2}$, Daiga Grinberga ${ }^{2}$, Kamelija Kadziauskiene ${ }^{3}$, Algis Abaraviciuss, Roma Bartkeviciute ${ }^{3}$, Sirje Vaask ${ }^{5}$, Aileen Robertson ${ }^{6}$ and Martin McKee ${ }^{7, *}$

${ }^{1}$ European Centre on Health of Societies in Transition, London School of Hygiene and Tropical Medicine, Keppel Street, London WC1E 7HT, UK: ${ }^{2}$ Health Education Division, Health Promotion Centre, Skolas 3, LV-1010 Riga, Latvia: ${ }^{3}$ National Nutrition Centre, Kalvariju str. 153, 2042 Vilnius, Lithuania: ${ }^{4}$ Faculty of Medicine, Department of Physiology and Biochemistry, Vilnius University, Ciurlionio str. 21/27, 2009 Vilnius, Lithuania: ${ }^{5}$ Public Health Department, Ministry of Social Affairs, Gonsiori str. 29, EE0100 Tallinn, Estonia: ${ }^{6}$ WHO Regional Officer for Europe, Scherfigsvej 8, DK-2 100 Copenhagen $\varnothing$, Denmark: ${ }^{7}$ European Centre on Health of Societies in Transition, London School of Hygiene and Tropical Medicine, Keppel Street, London WCIE 7HT, UK

Submitted 16 November 1998; Accepted 6 July 1999

\begin{abstract}
Objective: Previously recorded rates of obesity in the Baltic Republics have been among the highest in the world although little is known about how they vary within the population. This study investigates the distribution of body mass index (BMI) and obesity in these countries.

Design: Three cross-sectional surveys conducted in the summer of 1997.

Setting: Estonia, Latvia and Lithuania.

Subjects: Representative national samples of adults with measured weight and height (Estonia: $n=1154$; Latvia: $n=2292$; Lithuania: $n=2096$ ).

Results: Between-country differences are particularly large among women: women from Latvia and Lithuania are approximately three times as likely to be obese as those from Estonia (17.4\%, 18.3\%, 6.0\% respectively); only about one-third of this difference is explained by the sociodemographic and behavioural factors studied. In men, the prevalence of obesity varied only slightly among countries (Estonia: 9.9\%; Latvia: 9.5\%; Lithuania: 11.4\%). While the prevalence of obesity increases with age within each republic, particularly in women, it is not associated with nationality or urban/ rural region, and no consistent association is observed with income. Obesity is inversely related to education in Latvia and in Lithuanian women. Latvian men and women and Lithuanian men who smoked had a lower prevalence of obesity than non-smokers. Leisure time physical activity was not associated with obesity.

Conclusions: Obesity is a major health problem in the Baltic Republics, particularly among Latvian and Lithuanian women. The lack of association between obesity and most demographic, socioeconomic and behavioural factors suggests that the problem is generalized. Health promotion strategies aiming at preventing and controlling excess weight gain in the Baltic Republics will need to target the general population.
\end{abstract}

Keywords
Obesity
Diet
Latvia
Lithuania
Estonia
There is now a large volume of evidence showing that obesity is strongly associated with rates of total mortality, with those having a BMI greater than $30 \mathrm{~kg} \mathrm{~m}^{-2}$ (the standard definition of obesity) typically experiencing a relative risk of death that is more than double that of people of average weight ${ }^{1-3}$. Obesity is associated specifically with a range of common non-communicable diseases, such as hypertension ${ }^{4}$, cardiovascular disease ${ }^{5,6}$, stroke $^{7}$, certain cancers ${ }^{8,9}$ and diabetes mellitus ${ }^{10,11}$.

Obesity is an issue of particular concern in the Baltic Republics and in other parts of the former Soviet Union, where data from multinational surveys have found rates that are among the highest in the world. For example, data from the WHO MONICA study, collected between 1983 and 1988, placed the five centres in the former Soviet Union among the top six positions of 48 centres world-wide in terms of female obesity, with Kaunas in Lithuania occupying the highest position ${ }^{12}$. Among men the position of the former Soviet centres was not so bad, although here Kaunas ranked third overall.

These countries also have extremely high levels of many of the diseases associated with obesity. For example, the age-standardized death rates per 10000 people from ischaemic heart disease in 1994 were 410 in Estonia, 406 in Latvia and 397 in Lithuania, which contrast with the European Union average of $117^{13}$. However, while overall 
rates have been described, an effectively targeted public health strategy requires more detailed information, such as the distribution of obesity within the population. In this paper we describe the results of three surveys that address this question and that were undertaken in the Baltic Republics in 1997.

\section{Methods}

Surveys were conducted in each country during the summer of 1997. Each survey sought to include a representative sample of the national population aged between 19 and 64 years (19-65 in Lithuania). In each country, the sampling frames were the National Population Registers. All interviews were conducted in the individuals' own homes in the national language or in Russian.

In Estonia, a simple random sample of 3000 individuals, stratified by age, was drawn from the register. Interviewers did not return to a house if there was no reply. Substitution was allowed if the response rate in the county in question was less than $60 \%$. Overall, less than $5 \%$ of individuals, in seven counties, were substituted. Interviews were conducted by public health specialists, nutritionists and individuals with previous interviewing experience. Each attended a 1 day initial training session. The response rate was $67.3 \%$ and the final sample size was 2108 .

In Latvia, two-stage sampling was used to draw a sample of 3000 persons from the National Population Register. The first sampling stage selected a sample for each of the 26 regions in Latvia according to population size. In the second stage, random samples within strata were selected. The exception was for the city of Riga, where there appeared to be problems with the population register data, with a disproportionate number of people registered with ages over 60. Consequently, in Riga, the second stage sample was also stratified by age group. Interviewers were recruited from the regional environmental health centres. Substitution was not permitted and interviewers would return to an address up to five times. Each interviewer received training. The response rate was $77.7 \%$ and the final sample was 2331 .

In Lithuania, a sample of 3000 names was drawn at random from those individuals listed on the National Population Register who were living at addresses in Lithuania and who were aged between 20 and 65 . Interviewers were mainly assistants working in hygiene stations, who underwent an initial training session. In most cases the interviewers returned to an address on multiple occasions if they were unable to find the subject. There was no substitution. The response rate was $72.7 \%$ and the final sample size included 2182 respondents.

The proportion of men and women in the final samples was similar to that found in the general adult population of each country based on Statistical Yearbook data (1997 for Estonia and Latvia, and early 1998 for Lithuania - data available upon request). However, in Estonia, the respondents tended to be slightly younger than the general adult population; in Latvia and Lithuania they were slightly older. The distribution of the study groups by area of residence and nationality compared favourably with those of the general population.

Interviews included three parts: a 24-hour recall of dietary intake, the administration of a standardized questionnaire, and the measurement of height and weight. Results from the 24-hour recall are not described in this paper. The interviewer-administered questionnaire was developed and agreed by all countries. It was translated by professional translators from English into Estonian, Latvian, Lithuanian and Russian. Each country used the same Russian version of the questionnaire. The questionnaire covered demographic and socioeconomic characteristics (sex, age, nationality, educational achievement, income), health behaviours (cigarette smoking, physical activity level at work and during leisure time), selected dietary habits (e.g. vegetable intake, type of water used, etc.) and dietary beliefs. Respondents were also asked about their height without shoes and their weight without clothes or shoes. Nationality was classified as that of the native population, Russian or 'other'; the latter essentially equated to Ukrainian or Belarussian, or, in Lithuania, to Polish. The income variable related to average income per family member per month. In each country, it was divided into four categories based on selected national criteria for the poverty level, with the lowest category considered to be living in severe poverty. In Estonia, the cut-off point used for this lowest category was equivalent to the 'minimum basket for living' in 1997 (<US\$75 person ${ }^{-1}$ month $^{-1}$ ). In Latvia and Lithuania, as salaries are lower than in Estonia, a cut-off point of $<$ US\$50 person $^{-1}$ month $^{-1}$ was selected.

Measurements of height and weight were performed by the interviewers according to standardized procedures, with respondents without shoes in light clothing. Body mass index (BMI) was calculated as the weight in kilograms divided by the height in metres squared. Patterns of body weight described in this paper are based on measured height and weight. Standard definitions of relative body-weight status were used (underweight: BMI $<18.5 \mathrm{~kg} \mathrm{~m}^{-2}$; normal: BMI $18.5-24.9$; overweight: BMI 25-29.9; obese BMI $\geqslant 30)^{14}$.

In this study, we excluded pregnant women and respondents who did not have their height and weight measured. The numbers of male and female respondents in Latvia and Lithuania (Table 1) allowed a relative precision of between $15 \%$ and $28 \%(\alpha=0.05)$ for prevalence estimates between $5 \%$ and $15 \%$ in men and women ${ }^{15}$. However, the precision level decreased in the case of Estonia where a large proportion of respondents did not have their height and weight measured.

Data were analysed using the statistical package STATA version 5.0 (College Station, Texas). Between-country 


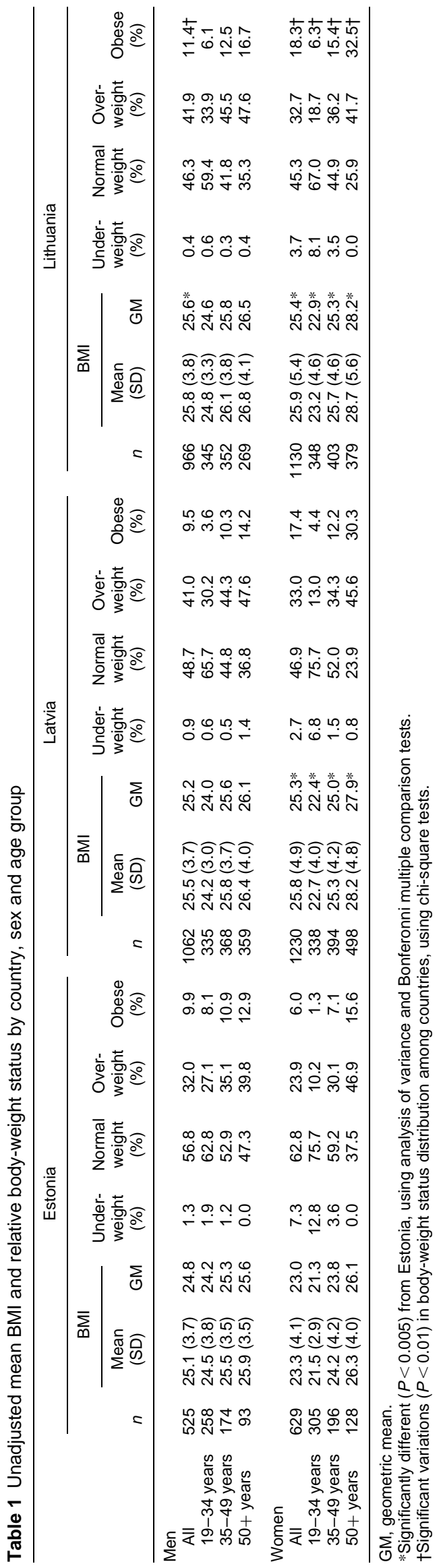

differences in unadjusted mean BMI and in the distribution of respondents by body-weight status were assessed using analyses of variance (with Bonferroni multiple comparison tests) and chi-square tests. As age and sex were strong determinants of obesity, the results were adjusted for age and they were presented separately for men and women. Age-adjusted means and proportions were calculated as the values predicted by the regression model with age held at its mean value. The odds of being obese according to a range of sociodemographic and behavioural variables were calculated using multiple logistic regression analyses with adjustment for all of the other variables. $\log _{\mathrm{e}}$-transformed values of BMI were used in the statistical analyses so that the skewness of the regression residuals was close to zero; transformed values were returned to their original units in the results section.

\section{Results}

The unadjusted mean BMIs and distribution of respondents by body-weight status are shown in Table 1. In each republic, the unadjusted mean BMI and prevalence of obesity increase with age. The increase in the prevalence of obesity is particularly striking in women: in Estonia, the prevalence is 12 times higher in women aged 50 years and over than in women less than 35 years old, in Latvia it is six times higher, and in Lithuania it is five times higher. In men, the prevalence of obesity increases with age by more than $50 \%$ in Estonia, it more than triples in Latvia and it more than doubles in Lithuania.

Among men, mean BMI is slightly higher in Lithuania and Latvia than in Estonia although the difference is only significant when all age groups are combined. Among women, there is rather more diversity. In all age groups, mean BMI is significantly higher in Latvia and in Lithuania than in Estonia. While there are relatively small differences in the distribution of BMI values in men (Fig. 1), the distribution of the whole population is shifted to the right in women from Latvia compared with women from Estonia, and it is shifted slightly further to the right in women from Lithuania (Fig. 2).

When the combined prevalence of overweight and obese people (BMI $\geqslant 25 \mathrm{~kg} \mathrm{~m}^{-2}$ ) is examined, over $40 \%$ of men from Estonia and more than half the male respondents from Latvia and Lithuania have an excess weight. This is the case in 30\% of women from Estonia, in $50 \%$ of those from Latvia and in 51\% of those from Lithuania. Excess weight is particularly prevalent in women aged 50 years and over in Latvia and Lithuania, three-quarters of them being overweight or obese. There are rather more obese men among the over fifties in Lithuania than in the other countries. Among women, the proportion who are obese in Latvia and Lithuania is almost three times that in Estonia. The difference is especially marked in women aged under 35 , with over four times as 


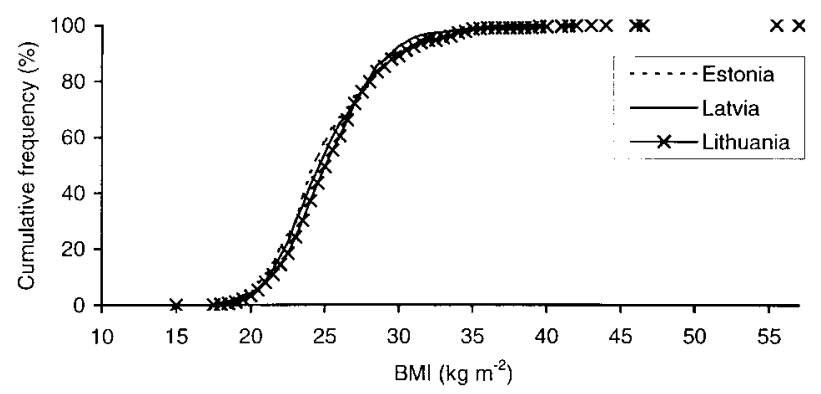

Fig. 1 Age-standardized cumulative frequency distribution of body mass index (BMI) by country in men

many women in Lithuania being obese compared with those in Estonia. Within each country, there were no clear differences between nationalities (Table 2), except for Russian men living in Latvia and Lithuania who were significantly less likely to be obese than Russian men living in Estonia $(P<0.05)$.

Table 3 shows the age-adjusted prevalence of obesity and the odds ratios for the likelihood of being obese in each country in relation to a range of sociodemographic variables. Consistent with the results in Table 2, there is no clear relationship with nationality in either men or women. In Latvia and Lithuania there is a clear increase in the likelihood of obesity with age in men (test for trend: $P<$ 0.01) and a suggestion that this is also the case in Estonia although the difference does not reach statistical significance. In women, the odds of obesity increases significantly with age in all three countries (test for trend: $P<0.001)$. There is no significant urban-rural difference in men and women and no consistent pattern with income. However, in Latvia, women in the highest income group are more than twice as likely to be obese than those in the lowest income group, and in Estonia, women in the third income category are eight times less

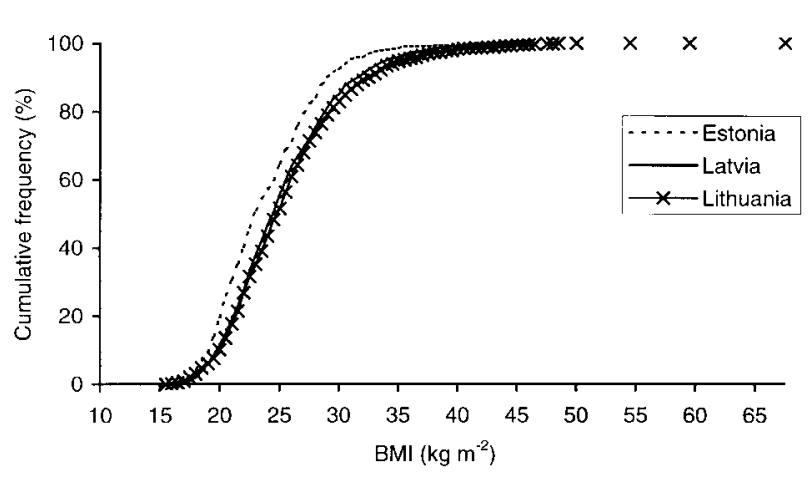

Fig. 2 Age-standardized cumulative frequency distribution of body mass index (BMI) by country in women

likely to be obese than those in the lowest income group. In Latvia, men with a secondary education or university degree are significantly less likely to be obese than men with lower education levels. In women, the likelihood of obesity is inversely related to educational achievement in both Latvia and Lithuania (test for trend: $P<0.05$ ); in Estonia, there is a tendency for women with higher educational achievement to be less obese than women having only primary level education but the differences do not reach statistical significance. In Latvia and Lithuania, men who are current smokers are less than half as likely as non-smokers to be obese. A similar finding is observed in women from Latvia. In Lithuania, the likelihood of obesity is inversely related to the level of physical activity at work in men (test for trend: $P=0.008$ ); men engaged in sedentary work are twice as likely to be obese as those in semisedentary or moderate/heavy work. There is no consistent pattern with leisure-time physical activity in either men or women. However, there appears to be a non-significant inverse relationship between leisure-time physical activity and obesity in Estonia.

Forward regression analyses were performed to

Table 2 Age-adjusted BMI and prevalence of obesity by country, sex and ethnicity

\begin{tabular}{|c|c|c|c|c|c|c|c|c|c|}
\hline & \multicolumn{3}{|c|}{ Estonia } & \multicolumn{3}{|c|}{ Latvia } & \multicolumn{3}{|c|}{ Lithuania } \\
\hline & $n$ & $\begin{array}{c}\text { Mean } \\
\text { BMl } \\
\left(\mathrm{kg} \mathrm{m}^{-2}\right)\end{array}$ & $\begin{array}{c}\text { Obesity } \\
(\%)\end{array}$ & $n$ & $\begin{array}{c}\text { Mean } \\
\text { BMl } \\
\left(\mathrm{kg} \mathrm{m}^{-2}\right)\end{array}$ & $\begin{array}{c}\text { Obesity } \\
(\%)\end{array}$ & $n$ & $\begin{array}{c}\text { Mean } \\
\text { BMl } \\
\left(\mathrm{kg} \mathrm{m}^{-2}\right)\end{array}$ & $\begin{array}{c}\text { Obesity } \\
(\%)\end{array}$ \\
\hline \multicolumn{10}{|l|}{ Men } \\
\hline Estonian & 455 & 24.8 & 9.0 & & & & & & \\
\hline Latvian & & & & 593 & 25.2 & 8.1 & & & \\
\hline Lithuanian & & & & & & & 802 & 25.6 & 11.7 \\
\hline Russian & 62 & 24.9 & 14.7 & 356 & 25.3 & 7.6 & 89 & 25.3 & 6.2 \\
\hline Others & 8 & 24.8 & 14.0 & 113 & 25.3 & 13.0 & 75 & 25.3 & 6.0 \\
\hline \multicolumn{10}{|l|}{ Women } \\
\hline Estonian & 531 & 22.9 & 3.3 & & & & & & \\
\hline Latvian & & & & 664 & 25.4 & 14.5 & & & \\
\hline Lithuanian & & & & & & & 965 & 25.5 & 15.9 \\
\hline Russian & 75 & 23.2 & 5.1 & 439 & 25.2 & 12.0 & 88 & 25.1 & 12.1 \\
\hline Others & 23 & 23.4 & 10.4 & 126 & 25.8 & 16.6 & 15 & 25.5 & 10.5 \\
\hline
\end{tabular}


Table 3a Age-adjusted prevalence of obesity and adjusted* odds ratios (OR) for the likelihood of being obese, by country, in men

\begin{tabular}{|c|c|c|c|c|c|c|c|c|c|c|c|c|}
\hline \multirow[b]{3}{*}{ Varable } & \multicolumn{4}{|c|}{ Estonia } & \multicolumn{4}{|c|}{ Latvia } & \multicolumn{4}{|c|}{ Lithuania } \\
\hline & \multirow[b]{2}{*}{$n$} & \multirow{2}{*}{$\begin{array}{l}\text { Obesity } \\
(\%)\end{array}$} & \multicolumn{2}{|c|}{$\begin{array}{l}\text { Adjusted* } \\
\text { odds of obesity }\end{array}$} & \multirow[b]{2}{*}{$n$} & \multirow{2}{*}{$\begin{array}{c}\text { Obesity } \\
(\%)\end{array}$} & \multicolumn{2}{|c|}{$\begin{array}{l}\text { Adjusted* } \\
\text { odds of obesity }\end{array}$} & \multirow[b]{2}{*}{$n$} & \multirow{2}{*}{$\begin{array}{l}\text { Obesity } \\
(\%)\end{array}$} & \multicolumn{2}{|c|}{$\begin{array}{l}\text { Adjusted* } \\
\text { odds of obesity }\end{array}$} \\
\hline & & & OR & $95 \% \mathrm{Cl}$ & & & OR & $95 \% \mathrm{Cl}$ & & & OR & $95 \% \mathrm{Cl}$ \\
\hline \multicolumn{13}{|l|}{ Nationality } \\
\hline Estonian & 455 & 9.0 & 1.00 & & 555 & 8.5 & 1.00 & & 707 & 11.5 & 1.00 & \\
\hline Russian & 62 & 14.7 & 1.83 & $0.80-4.20$ & 323 & 7.8 & 1.04 & $0.61-1.78$ & 73 & 7.6 & 0.64 & $0.26-1.56$ \\
\hline Other & 8 & 14.0 & 1.92 & $0.20-18.32$ & 106 & 12.9 & 1.42 & $0.75-2.69$ & 64 & 4.3 & 0.38 & $0.11-1.24$ \\
\hline \multicolumn{13}{|l|}{ Age group } \\
\hline$<35$ years & 258 & 8.1 & 1.00 & & 307 & 3.6 & 1.00 & & 295 & 6.1 & 1.00 & \\
\hline $35-49$ years & 174 & 10.9 & 1.30 & $0.66-2.57$ & 338 & 10.4 & 3.17 & $1.55-6.47$ & 314 & 12.1 & 2.43 & $1.33-4.44$ \\
\hline $50+$ years & 93 & 12.9 & 1.92 & $0.84-4.36$ & 339 & 15.0 & 3.74 & $1.83-7.64$ & 235 & 16.2 & 2.42 & $1.27-4.60$ \\
\hline \multicolumn{13}{|l|}{ Region } \\
\hline Urban & 336 & 10.2 & 1.00 & & 637 & 8.5 & 1.00 & & 558 & 11.5 & 1.00 & \\
\hline Rural & 189 & 8.9 & 1.04 & $0.55-1.99$ & 347 & 9.2 & 1.18 & $0.71-1.97$ & 286 & 8.9 & 0.81 & $0.48-1.37$ \\
\hline \multicolumn{13}{|l|}{ Education } \\
\hline Primary & 52 & 3.2 & 1.00 & & 212 & 12.8 & 1.00 & & 189 & 10.2 & 1.00 & \\
\hline Secondary & 250 & 10.7 & 3.47 & $0.76-15.98$ & 310 & 5.3 & 0.35 & $0.19-0.67$ & 213 & 10.5 & 0.96 & $0.49-1.91$ \\
\hline University† & 223 & 10.2 & 2.99 & $0.65-13.82$ & 462 & 9.3 & 0.57 & $0.33-0.98$ & 442 & 10.9 & 0.87 & $0.46-1.61$ \\
\hline \multicolumn{13}{|l|}{ Income } \\
\hline Level 1 (lowest) & 108 & 9.6 & 1.00 & & 341 & 8.1 & 1.00 & & 333 & 9.8 & 1.00 & \\
\hline Level 2 & 202 & 9.6 & 0.89 & $0.40-2.00$ & 439 & 8.0 & 1.07 & $0.63-1.83$ & 229 & 9.5 & 0.79 & $0.44-1.42$ \\
\hline Level 3 & 147 & 7.6 & 0.73 & $0.29-1.85$ & 125 & 9.1 & 1.41 & $0.63-3.12$ & 97 & 11.6 & 1.02 & $0.47-2.18$ \\
\hline Level 4 (highest) & 68 & 14.9 & 1.56 & $0.58-4.20$ & 79 & 14.9 & 1.96 & $0.85-4.54$ & 185 & 13.1 & 1.07 & $0.56-2.02$ \\
\hline \multicolumn{13}{|l|}{ Smoking } \\
\hline Non-smoking & 184 & 12.1 & 1.00 & & 327 & 13.4 & 1.00 & & 291 & 16.3 & 1.00 & \\
\hline Current smoker & 341 & 8.5 & 0.65 & $0.35-1.21$ & 657 & 6.5 & 0.43 & $0.27-0.67$ & 553 & 7.7 & 0.42 & $0.26-0.66$ \\
\hline \multicolumn{13}{|l|}{ Work activity } \\
\hline Sedentary & 166 & 12.3 & 1.00 & & 167 & 6.7 & 1.00 & & 150 & 17.1 & 1.00 & \\
\hline Semisedentary & 156 & 12.1 & 1.04 & $0.52-2.08$ & 353 & 9.3 & 1.57 & $0.79-3.12$ & 280 & 10.8 & 0.54 & $0.30-0.97$ \\
\hline Moderate/heavy & 203 & 5.8 & 0.53 & $0.25-1.14$ & 464 & 9.0 & 1.51 & $0.77-2.99$ & 414 & 8.2 & 0.43 & $0.24-0.78$ \\
\hline \multicolumn{13}{|c|}{ Leisure-time physical activity } \\
\hline Sedentary & 261 & 11.9 & 1.00 & & 522 & 7.8 & 1.00 & & 540 & 10.8 & 1.00 & \\
\hline Moderate & 149 & 8.0 & 0.69 & $0.33-1.45$ & 275 & 8.1 & 0.92 & $0.54-1.57$ & 128 & 8.3 & 0.57 & $0.28-1.16$ \\
\hline High & 115 & 7.0 & 0.54 & $0.23-1.27$ & 187 & 12.2 & 1.39 & $0.79-2.47$ & 176 & 11.8 & 0.93 & $0.53-1.62$ \\
\hline
\end{tabular}

*Odds ratio are adjusted for all the other variables in the multivariate logistic regression analysis.

tUniversity and secondary special. 
Table 3b Age-adjusted prevalence of obesity and adjusted* odds ratios (OR) for the likelihood of being obese, by country, in women

\begin{tabular}{|c|c|c|c|c|c|c|c|c|c|c|c|c|}
\hline \multirow[b]{3}{*}{ Variable } & \multicolumn{4}{|c|}{ Estonia } & \multicolumn{4}{|c|}{ Latvia } & \multicolumn{4}{|c|}{ Lithuania } \\
\hline & \multirow[b]{2}{*}{$n$} & \multirow{2}{*}{$\begin{array}{l}\text { Obesity } \\
(\%)\end{array}$} & \multicolumn{2}{|c|}{$\begin{array}{c}\text { Adjusted* } \\
\text { odds of obesity }\end{array}$} & \multirow[b]{2}{*}{$n$} & \multirow{2}{*}{$\begin{array}{c}\text { Obesity } \\
(\%)\end{array}$} & \multicolumn{2}{|c|}{$\begin{array}{c}\text { Adjusted* } \\
\text { odds of obesity }\end{array}$} & \multirow[b]{2}{*}{$n$} & \multirow{2}{*}{$\begin{array}{c}\text { Obesity } \\
(\%)\end{array}$} & \multicolumn{2}{|c|}{$\begin{array}{c}\text { Adjusted* } \\
\text { odds of obesity }\end{array}$} \\
\hline & & & OR & $95 \% \mathrm{Cl}$ & & & OR & $95 \% \mathrm{Cl}$ & & & OR & $95 \% \mathrm{Cl}$ \\
\hline \multicolumn{13}{|l|}{ Nationality } \\
\hline Estonian & 531 & 3.3 & 1.00 & & 624 & 14.5 & 1.00 & & 881 & 14.8 & 1.00 & \\
\hline Russian & 75 & 5.1 & 1.03 & $0.33-3.20$ & 413 & 12.0 & 0.83 & $0.57-1.19$ & 77 & 13.1 & 0.85 & $0.42-1.69$ \\
\hline Other & 23 & 10.4 & 2.87 & $0.76-10.84$ & 121 & 17.1 & 1.06 & $0.63-1.80$ & 64 & 10.2 & 0.62 & $0.28-1.37$ \\
\hline \multicolumn{13}{|l|}{ Age group } \\
\hline$<35$ years & 305 & 1.3 & 1.00 & & 314 & 4.1 & 1.00 & & 320 & 5.6 & 1.00 & \\
\hline $35-49$ years & 196 & 7.1 & 5.63 & $1.75-18.13$ & 372 & 12.6 & 3.41 & $1.79-6.49$ & 369 & 15.2 & 3.07 & $1.75-5.37$ \\
\hline $50+$ years & 128 & 15.6 & 10.54 & $3.14-35.35$ & 472 & 30.5 & 7.47 & $4.06-13.73$ & 333 & 31.2 & 6.22 & $3.49-11.08$ \\
\hline \multicolumn{13}{|l|}{ Region } \\
\hline Ürban & 447 & 3.5 & 1.00 & & 775 & 13.7 & 1.00 & & 694 & 13.0 & 1.00 & \\
\hline Rural & 182 & 4.3 & 1.26 & $0.58-2.74$ & 383 & 14.2 & 0.83 & $0.57-1.22$ & 328 & 17.5 & 1.26 & $0.86-1.86$ \\
\hline \multicolumn{13}{|l|}{ Education } \\
\hline Primary & 39 & 8.5 & 1.00 & & 213 & 22.8 & 1.00 & & 177 & 20.1 & 1.00 & \\
\hline Secondary & 282 & 3.9 & 0.40 & $0.15-1.09$ & 376 & 12.0 & 0.41 & $0.26-0.64$ & 250 & 15.4 & 0.63 & $0.37-1.07$ \\
\hline University† & 308 & 3.2 & 0.38 & $0.13-1.07$ & 569 & 12.4 & 0.41 & $0.27-0.62$ & 595 & 12.6 & 0.54 & $0.33-0.88$ \\
\hline \multicolumn{13}{|l|}{ Income } \\
\hline Level 1 (lowest) & 163 & 4.9 & 1.00 & & 441 & 14.8 & 1.00 & & 370 & 17.4 & 1.00 & \\
\hline Level 2 & 282 & 4.6 & 1.01 & $0.47-2.16$ & 555 & 12.9 & 1.02 & $0.70-1.47$ & 316 & 14.6 & 0.91 & $0.61-1.38$ \\
\hline Level 3 & 145 & 0.5 & 0.12 & $0.01-0.97$ & 108 & 10.1 & 0.82 & $0.41-1.63$ & 123 & 12.4 & 0.76 & $0.42-1.37$ \\
\hline Level 4 (highest) & 39 & 5.8 & 1.28 & $0.25-6.59$ & 54 & 23.5 & 2.30 & $1.08-4.88$ & 213 & 10.3 & 0.65 & $0.37-1.12$ \\
\hline \multicolumn{13}{|l|}{ Smoking } \\
\hline Non-smoking & 367 & 3.3 & 1.00 & & 923 & 15.0 & 1.00 & & 846 & 13.5 & 1.00 & \\
\hline Current smoker & 262 & 4.3 & 1.08 & $0.49-2.36$ & 235 & 9.9 & 0.52 & $0.31-0.87$ & 176 & 18.5 & 1.40 & $0.86-2.30$ \\
\hline \multicolumn{13}{|l|}{ Work activity } \\
\hline Sedentary & 254 & 4.1 & 1.00 & & 265 & 15.2 & 1.00 & & 263 & 13.5 & 1.00 & \\
\hline Semisedentary & 253 & 2.2 & 0.53 & $0.21-1.33$ & 669 & 13.0 & 0.78 & $0.52-1.15$ & 526 & 15.5 & 1.03 & $0.66-1.60$ \\
\hline Moderate/heavy & 122 & 6.7 & 1.65 & $0.65-4.24$ & 224 & 14.9 & 0.86 & $0.52-1.43$ & 233 & 12.8 & 0.70 & $0.41-1.20$ \\
\hline \multicolumn{13}{|c|}{ Leisure-time physical activity } \\
\hline Sedentary & 212 & 5.4 & 1.00 & & 584 & 15.5 & 1.00 & & 578 & 14.3 & 1.00 & \\
\hline Moderate & 311 & 2.6 & 0.52 & $0.23-1.19$ & 386 & 12.5 & 0.78 & $0.53-1.15$ & 219 & 11.5 & 0.79 & $0.49-1.27$ \\
\hline High & 106 & 3.6 & 0.49 & $0.15-1.66$ & 188 & 11.8 & 0.66 & $0.40-1.11$ & 225 & 17.3 & 1.29 & $0.85-1.95$ \\
\hline
\end{tabular}

*Odds ratios are adjusted for all the other variables in the multivariate logistic regression analysis.

†University and secondary special. 
Table 4 Odds ratios for the likelihood of being obese in women from Latvia and Lithuania compared with women from Estonia

\begin{tabular}{lllr}
\hline Variables included in the multiple regression model* & Country & OR & $95 \% \mathrm{Cl}$ \\
\hline & Estonia & 1.00 & \\
& Latvia & 3.33 & $2.32-4.77$ \\
Age & Lithuania & 3.28 & $2.28-4.73$ \\
& Estonia & 1.00 & \\
Age + Education & Latvia & 2.31 & $1.59-3.36$ \\
& Lithuania & 2.60 & $1.79-3.80$ \\
& Estonia & 1.00 & \\
Age + Education + Leisure-time physical activity & Latvia & 2.18 & $1.50-3.17$ \\
& Lithuania & 2.38 & $1.62-3.48$ \\
& Estonia & 1.00 & \\
Age + Education + Leisure-time physical activity + Income & Latvia & 2.10 & $1.44-3.06$ \\
& Lithuania & 2.24 & $1.52-3.30$ \\
& Estonia & 1.00 & \\
& Latvia & 2.02 & $1.38-2.95$ \\
& Lithuania & 2.20 & $1.48-3.25$ \\
\hline
\end{tabular}

*Factors were included in the model using a stepwise approach using $P<0.25$. Factors were selected among: age, region (urban/rural), education level, income level, current smoking, work activity and leisure-time physical activity.

investigate whether between-country differences in the prevalence of obesity in women could be explained by selected sociodemographic factors and health behaviours (Table 4). When variations in age, educational achievement, leisure-time physical activity level and income status are taken into account, the difference in the odds of being obese between Estonia and Latvia decreases by 39\% and the difference between Estonia and Lithuania by $33 \%$. However, the differences remain significant.

\section{Discussion}

For the first time, these data provide evidence about the distribution of body weight in national samples in the Baltic Republics. The proportion of women in Lithuania who are obese is lower than in the earlier MONICA sample. This could conceivably be due to differences in sampling and it cannot be assumed that the difference is due to a real change. The rates for men in the two studies are broadly comparable.

The present study demonstrates a general shift to the right in the distribution of BMI in women from Latvia and Lithuania compared with women from Estonia, and corresponding higher rates of obesity. In contrast, rates of obesity in Estonia, at least among young women, compare favourably with those in countries such as Sweden ${ }^{16}$ and the Netherlands ${ }^{17}$, although even here there are no grounds for complacency. The difference in the prevalence of obesity between women from Estonia and those from Latvia and Lithuania could not be explained entirely by the sociodemographic and behavioural factors investigated in this study. Only approximately one-third of the difference is explained by variations in age, educational achievement, leisure-time physical activity level and income status, and the odds of being obese remain twice as high in Latvia and Lithuania than in Estonia after adjusting for these variables.
Within each country, the prevalence of obesity does not vary significantly with ethnicity. Furthermore, contrary to findings reported by other researchers ${ }^{18}$, there is no consistent variation in the odds of being obese according to demographic and socioeconomic characteristics, suggesting that the problem affects most population subgroups in the Baltic Republics. The only exception is for the inverse relationship between education level and the likelihood of obesity in women (although not significant in women from Estonia) and in men from Latvia.

In accordance with findings from other investigators ${ }^{18-20}$, smoking is associated with a lower prevalence of obesity in some respondents, that is, men and women from Latvia, men from Lithuania, and a suggestion that this is also the case in men from Estonia. However, the odds of being obese is seldom related to physical activity level at work or during leisure time $\mathrm{e}^{20-22}$. This lack of association could be related to the fact that the questionnaires used in the surveys included only general questions on physical activities. More detailed assessment of physical activity level in men and women from the Baltic Republics will be necessary for the development of effective strategies for the prevention of obesity.

The steady increase in mean BMI and in the prevalence of obesity with age in all three countries suggests that the underlying effects of weight gain with age could accentuate the risks of cardiovascular diseases in the Baltic states. It also suggests that obesity prevention in young adults should be a primary goal in health promotion strategies in order to prevent weight gain with ageing.

In conclusion, this study suggests that obesity is a major health problem in the Baltic Republics, particularly among women in Latvia and Lithuania. The lack of association observed between obesity and most demographic, socioeconomic and behavioural factors studied suggests that the problem is more generalized than expected and that health promotion strategies aiming at preventing and 
controlling excess weight gain in each Baltic Republic will need to target the population as a whole. A more complete exploration of the correlates of obesity in the Baltic Republic, including more precise assessments of modifiable lifestyle behaviours such as physical activity and dietary intake, would contribute not only to understanding the determinants of obesity in these countries but also to defining what strategies are most likely to be effective in preventing and reducing obesity in each republic. Finally, the establishment of national surveillance systems of obesity in the Baltic Republics would facilitate the planning of preventive and obesity management programmes in order to prevent any upward trend in the prevalence of obesity in these countries.

\section{References}

1 Seidell JC, Vershuren WM, van Leer EM, Kromhout D. Overweight, underweight, and mortality. A prospective study of 48,287 men and women. Arch. Intern. Med. 1996; 156: $958-69$.

2 Manson JE, Willett WC, Stampfer MJ. Body weight and mortality among women. N. Engl.J. Med. 1995; 333: 677-85.

3 Rissanen A et al. Risk of disability and mortality due to overweight in a Finnish population. BMJ 1990; 301: 835-7.

4 Van Itallie TB. Health implications of overweight and obesity in the United Staes. Ann. Intern. Med. 1985; 103: 983-8.

5 Hubert HB, Feinleib M, McNamara PM, Castelli WP. Obesity as an independent risk factor for cardiovascular disease: a 26 year follow-up of participants in the Framingham Heart Study. Circulation 1983; 67: 968-77.

6 Jousilahti P, Tuomilehto J, Vartiainen E, Pekkanen J, Puska P. Body weight, cardiovascular risk factors, and coronary mortality: 15 year follow-up of middle-aged men and women in eastern Finland. Circulation 1996; 93: 1372-9.

7 Abbott RD et al. Body mass index and thromboembolic stroke in nonsmoking men in older middle age. The Honolulu Heart Program. Stroke 1994; 25: 2370-6.

8 Schapiro DV et al. Visceral obesity and breast cancer risk. Cancer 1994; 74: 632-9.

9 Le Marchand L, Wilkens LR, Mi MP. Obesity in youth and middle age and risk of colorectal cancer in men. Cancer Causes Control 1992; 3: 349-54

10 Schaten BJ, Smith GD, Kuller LH, Neaton JD. Risk factors for the development of type II diabetes among men enrolled in the usual care group in the Multiple Risk Factor Intervention Trial. Diabetes Care 1994; 17: 288-96.

11 Chan JM, Rimm EB, Colditz GA, Stampfer MJ, Willett WC. Obesity, fat distribution and weight gain as risk factors for clinical diabetes in men. Diabetes Care 1994; 17: 961-9.

12 WHO MONICA Project. Geographical variation in the major risk factors of coronary heart disease in men and women aged 35-64 years. World Health Stat. Q. 1988; 41: 115-40.

13 WHO. Health for all database. Copenhagen: WHO, 1998.

14 WHO. Physical Status: the Use and Interpretation of Anthropometry. Report of a WHO Expert Committee. Technical Report Series No. 854. Geneva: WHO, 1995.

15 Lwanga SK, Lemeshow S. Sample Size Determination in Health Studies. A Practical Manual. Geneva: WHO, 1991.

16 Kuskowska-Wolk A, Bergstrom R. Trends in body mass index and prevalence of obesity in Swedish women 198089. J. Epidemiol. Community Health 1993; 47: 195-9.

17 Seidell JC. Time trends in obesity: an epidemiological perspective. Horm. Metab. Res. 1997; 29: 155-8.

18 Seidell JC. Obesity in Europe: scaling an epidemic. Int. J. Obes. 1995; 19 (Suppl. 3): S1-4.

19 Klesges RC, Klesges LM. The relationship between body mass and cigarette smoking using a biochemical index of smoking exposure. Int. J. Obes. 1993; 17: 585-91.

20 Bennett N, Dodd T, Flatley J, Freeth S, Bolling K. Health Survey for England 1993. London: HMSO, 1995.

21 Williamson DF, Madans J, Anda RF, Kleinman JC, Kahn HS, Byers T. Recreational physical activity and ten-year weight change in a US national cohort. Int. J. Obes. 1993; 17: 279-86.

22 De Groot LCPGM, van Staveren WA. Reduced physical activity and its association with obesity. Nutr. Rev. 1995; 53 $11-13$. 